\title{
Legal Regulations for Managing the Surrounding Aerobic Environment in Athletic Institutions in order to Achieve Sustainable Development
}

\author{
Prof. Dr. Hassan Ahmed El-Shafee ${ }^{(*)}$ \\ Asst. Prof. Dr. Samah Ahmed Salah Al-Din ${ }^{(* *)}$ \\ Asst. Prof. Dr. Donia Mohamed Adel Abdel-Aziz ${ }^{(* *)}$
}

\section{Research problem and its significance:}

By the end of twentieth century, the issues, management, and protection of the environment have attracted the whole world's attention. As many countries in the world are experiencing a decline and regression in their savings from natural resources and thus a lot of environmental pollution problems appeared. And as we are not in isolation from the world and are influenced by what is around us, great attention has been given to the environmental protection and the development of resources, working on finding a balance between requirements and environmental considerations and the rational use of available resources and development in various areas of culture, legal, environment, health, and sports. [5]

The field of sports is closely related to nature and the environment, thus it urges the organizations and bodies concerned with sport to educate athletes on the importance of preserving the environment through the use of available resources to meet their current needs without compromising the capacity of these resources to renewal to meet the future needs of subsequent generations which ensure sustainability. [3]

This is confirmed by the results of Hameema Hasheesh and others studies (2010) which identified the importance of the environmental dimension of investment projects in sports and which focused on raising cultural, social, and environmental awareness. As well as introducing the ecological balance of the environment protection from all kinds of pollution and depletion. It recommended the need to integrate the environmental dimension in sporting institutions strategies to ensure their contribution to the achievement of sustainable development and the formation of sports economic institutions of the national economy. [15]

The International Olympic Committee had pointed out the need to encourage and educate all stakeholders related to the Olympic movement and the environmental problems, in order to raise their awareness of the importance of sustainable development. Thus, the environment has become one of the

\footnotetext{
(*) Professor of Physical Management, Physical Management Department, Faculty of Physical Education Girls departure, Alexandria University ${ }^{(* *)}$ Assistant Professor, Physical Management Department, Faculty of Physical Education Girls departure, Alexandria University
} 
main priorities of the International Olympic Committee where it is regarded as the third dimension of the Olympic movement, and one of the most important criteria for evaluating and selecting the cities hosting the Olympic Games.

Many international organizations have tended to administrative cooperation and coordination towards environmental protection between the relevant authorities with environmental safety. Numerous conferences were held, including the second Gulf conference on sport and environment in local and regional tournaments for the Gulf Cooperation Council in Doha(2011). It recommended a cooperation mechanism between the ministries of environment and sports and the National Olympic committees and sports championships. More, the regulatory committees urged the need for the observance of the environmental norms in the Organization of sporting events. [17]

Many scientific conferences confirmed that the environmental air pollution, as it affects normal individuals, affects a greater proportion of athletes, especially professional ones because athletes need more natural pure oxygen, which has become now polluted and dangerous that might expose the athletes to disease and even lead to the possibility of sudden death. [2] [13]

Therefore, many studies have tended to study the problem of pollution and its serious risk to the human health, especially to the practitioners of the sport and physical activity. A direct link between air pollution and chest diseases has been found. It was due to air pollution that most athletes suffer from breathing difficulties and chest diseases as well as nausea and stress. The studies of Assad Adnan (2010) [1], Ali Hussein (2010) [7], and Mousa Ibrahim (2003) [13] have declared that air pollution has a negative impact on the level of some physiological variables walbiokimiaeh in the blood and some certain physical attributes, especially on children and youth-the backbone of development and progress- which lead to a bad effect on the national income and tourism sector. They also recommended the necessity of building stadiums and training areas that have less pollution level to protect the health of practitioners for sports activity.

According to the results of the first survey [appendix 1] and the team knowledge there is clear absence of a law for the environment in addition to a lack in any connection between them and the bodies concerned with environmental affairs to take the necessary action to maintain the sustainability of sport institutions.

The Working team also conducted another survey [appendix 2] which was a personal interview with some environmental officials in the Environment Research Institute, Environmental Affairs Department in Alexandria, in order to identify the places of air pollution and its levels across the province. In addition to identifying the different studies concerned with the same subject. The results verified that the contamination rates in the areas of air pollution in Alexandria are undetermined and that there are no annual statistics on the proportion of pollution. The results also confirmed that the sports clubs and their officials have no direct contact with the institute when creating sports projects in residential areas, and that there is a lack of scientific research in the subject of air pollution as one of the officials referred to the existence of one study only that mentioned the specific ratios of air pollution of 1980.

The Working Group found out that the Environmental Law decides certain healthy air conditions that must be taken into consideration when creating and building various projects, while the state must ensure the monitoring and follow-up of such projects. 
Due to the fact that the working group discovered that this topic was only tackled by a few researchers in the Physical Education field at the Arab Republic of Egypt, they conducted this study to handle an important aspect of this issue which is to reveal the legal regulation and the extent to which its related to air environmental management to achieve sustainable development.

\section{Research Objectives}

Developing proposed legal regulation for managing the surrounding aerobic environment in athletic institutions in order to achieve sustainable development through the identification of:

1- The concept and importance of environmental management in athletic institutions in order to achieve sustainable development

2- Requirements and specifications for choosing and building projects in athletic institutions

3- Awareness of legislation and laws for the environmental management to achieve sustainable development in athletic institutions.

\section{Research Questions:}

1. What is the concept and importance of environmental management in athletic institutions?

2. What are the requirements and specifications for choosing and building projects in athletic institutions?

3. What are the laws and legislation for managing the surrounding aerobic environment to achieve sustainable development in athletic institutions?

\section{Procedures}

\section{Research Methodology}

The research team used the descriptive approach as it is suitable for nature of the research.

\section{Research community}

Research team targeted intentional sample from more active Sport Unions board of directors members (swimming - football - Handball - Basketball - Volleyball- Gymnastics) and big clubs in Alexandria and Behaira (Smouha - Sporting - Olympic - Ittihad - Chrom - Damanhur) and sophisticated youth centers (Oboor - Mattarya - Smouha - Seyouf - Kabbari - Shalalat)

\section{Research Sample}

The total sample was 180 individuals, distributed among foregoing athletic institutions as following: 60 individuals from Sport Unions, 60 individuals from sports clubs, 60 individuals from youth centers. 30 individuals were selected randomly for the survey and excluded from the main sample, so the main study sample was 150 individuals. 


\section{Data collection}

The research team used:

- The research team used the questionnaire as a tool for data collection, following these steps to resolve the outcome of the regulations and documents related to the subject of the study: Environmental law No. 4 for 1994 year [8], ISO standard No. 14001 [12], The UNESCO International Charter for physical education [4] , The United Nations Charter for the principles of sustainable development [14], Youth and Sport institutions Law for 2000 year [9], Meeting with some sports clubs and youth centers officials and members First attachment.

- Meetings with some specialists and experts in the field of environmental affairs second attachment.

- $\quad$ scientific references and results of similar studies to the topic in concern

Through the preceding steps the axes and dimensions of the questionnaire were specified third attachment and were presented to eight professors and assistant professors in the areas of sports and environment fourth attachment, to ensure the validity of the axes and dimensions. Accordingly, identification and formulation terms under each axis included 30 phrases that were presented to the experts in their initial image fifth attachment for comment. Which resulted in deleting and amending the wording of some phrases according to the opinion of their majority. Thus the questionnaire sixth attachments was developed in its final form, and ready for application, after completing the experts' 29 adjustments where 2 phrases were deleted, wording has been modified in figures 12, 14, 20.

\section{Questionnaire scientific transactions:}

\section{First: questionnaire validity}

\section{Validity was calculated in two ways:}

A. arbitrator validity: The research team adopted on arbitrator validity, to recognize the relevance and clarity of themes and phrases as they had deleted and modified some phrases.

B. internal coherence validity: correlation coefficients were calculated between axis degrees, and after the questionnaire total degree range between (0.694: 0.732), and function at a level (0.01), indicating internal coherence validity between the axis degrees and dimensions and the questionnaire total degree. Thus, the questionnaire indicates a high degree of validity.

\section{Second: questionnaire Reliability}

Reliability was calculated by: Using Alpha Cronbach's on a survey sample of 30 individuals ranging between (0.723: 0.855). Questionnaire reliability was 0.9775 , indicating a high degree of reliability for the axes and dimensions of the questionnaire and applicability of the six attachments .

\section{Time domain}

Basic study was applied in the period from $22 / 1 / 2014$ to $27 / 2 / 2014$. 


\section{Statistic methods}

Frequencies, percentage, validity (alpha Cronbach's), Chi square.

\section{Results Presentation and Discussion}

1- The First aspect: the concept and importance of the management the surrounding aerobic environment for athletic institutions

\section{Table (1)}

Frequencies, percentages and Chi square values for research sample responses to the first aspect statements $(n=150)$

\begin{tabular}{|c|c|c|c|c|c|}
\hline \multirow[t]{2}{*}{ Statement N } & \multicolumn{2}{|l|}{ Yes } & \multicolumn{2}{|l|}{ No } & \multirow[t]{2}{*}{ Chi square v } \\
\hline & Frequency & $\%$ & Frequency & $\%$ & \\
\hline \multicolumn{6}{|c|}{ Sub-aspect 1} \\
\hline 1 & 138 & 92.00 & 12 & 8.00 & 105.84 \\
\hline 2 & 143 & 95.33 & 7 & 4.67 & 123.31 \\
\hline 3 & 135 & 90.00 & 15 & 10.00 & 96.00 \\
\hline 4 & 142 & 94.67 & 8 & 5.33 & 119.71 \\
\hline 5 & 139 & 92.67 & 11 & 7.33 & 109.23 \\
\hline 6 & 138 & 92.00 & 12 & 8.00 & 105.84 \\
\hline \multicolumn{6}{|c|}{ Sub-aspect 2} \\
\hline 7 & 142 & 94.67 & 8 & 5.33 & 119.71 \\
\hline 8 & 135 & 90.00 & 15 & 10.00 & 96.00 \\
\hline 9 & 139 & 92.67 & 11 & 7.33 & 109.23 \\
\hline 10 & 135 & 90.00 & 15 & 10.00 & 96.00 \\
\hline 11 & 135 & 90.00 & 15 & 10.00 & 96.00 \\
\hline 12 & 142 & 94.67 & 8 & 5.33 & 119.71 \\
\hline 13 & 139 & 92.67 & 11 & 7.33 & 109.23 \\
\hline 14 & 138 & 92.00 & 12 & 8.00 & 105.84 \\
\hline 15 & 135 & 90.00 & 15 & 10.00 & 96.00 \\
\hline 16 & 142 & 94.67 & 8 & 5.33 & 119.71 \\
\hline
\end{tabular}

Chi square tabular value at significant level $(0.05)=5.99$

Table (1) results reveal that Chi square calculated values are greater than its tabular value at (0.05) significance level, which indicates presence of statistically significant differences between the research sample responses. The differences were in favor of the yes response.

Most research sample responses approved with percentage ranged between (90.00: 94.67\%), approved that the concept of management the surrounding aerobic environment for athletic institutions 
illustrated in creating a set of policies, procedures, commitments and working plans which prevent pollution of the aerobic environment for areas. In this regard both of (Mohamed Samir, 2012) [11], and (El-Saud 2004) [5]confirmed that the environment protection and the development strategies to a large extent correspond with the development of these circumstances, they are two linked aspects that cannot be separated, due to the human beings ability to improve their living standard and create suitable conditions for the coming generations. The study results of (Mohsen Mohamed, 2009) [10] confirmed that relying on the scientific side in dealing with the environment, either through scientific planning based on scientific grounds and current and future expectations, or through guides and recommendations, will lead to reducing the environmental risks so that there is no detrimental effect to the interaction process of the environment components in which it is going according to continuous self- movement to maintain ecological balance in order to sustain life.

Most research sample responses also approved with a percentage ranging between (90.00: $94.67 \%$ ) that the aerobic environment management's importance obliges organizations to respect all legislation and regulations to protect the environment and stresses the need to increase environmental awareness to stop pollution and repair damaged ones. This was confirmed by the studies of (El-Saud , 2004) [5] who emphasized the role of the environmental conferences and seminars that were held in various regions of the world in developing a more aware world population of the environment and its problems, and that possesses the knowledge, skills, attitudes and commitment in both individual and in team work, to enable them to solve the already existing problems and to avoid new ones.

The Second aspect: Requirements and specifications for choosing and building projects in athletic institutions

Table (2)

Frequencies, percentages and Chi square values for research sample responses for the second aspect statements $(n=150)$

\begin{tabular}{|l|l|l|l|l|l|}
\hline Statement & Yes & \multicolumn{3}{l}{ No } & Chi square v \\
\hline & Frequency & $\%$ & Frequency & $\%$ & \\
\hline 17 & 138 & 92.00 & 12 & 8.00 & 105.84 \\
\hline 18 & 143 & 95.33 & 7 & 4.67 & 123.31 \\
\hline 19 & 135 & 90.00 & 15 & 10.00 & 96.00 \\
\hline 20 & 142 & 94.67 & 8 & 5.33 & 119.71 \\
\hline 21 & 139 & 92.67 & 11 & 7.33 & 109.23 \\
\hline 22 & 138 & 92.00 & 12 & 8.00 & 105.84 \\
\hline 23 & 142 & 94.67 & 8 & 5.33 & 119.71 \\
\hline 24 & 135 & 90.00 & 15 & 10.00 & 96.00 \\
\hline 25 & 139 & 92.67 & 11 & 7.33 & 109.23 \\
\hline
\end{tabular}

Chi square value at (0.05) level $=5.99$ 
Table (2 ) shows Chi square calculated values results greater than its tabulated value at (0.05) significance level, which indicates the presence of statistically significant differences between the research sample responses, in favor of yes response.

Most research sample responses also agreed with a percentage that ranged between (92.00: 95.33) that the requirements and specifications that must be considered when choosing and building projects in athletes institutions to achieve sustainable development's objectives stressed on the need for organization sit appropriateness, in terms of the nature of the division of the region, in accordance with the plan of the Ministry of Housing and Urban Communities. It also stresses the importance of having the site of agricultural areas and watercourses in accordance with specifications and regulations and minimum distance from these areas. This appeared in (Adnan,2010) [1] study results which confirmed that the air pollution has a negative impact on the health of sport practitioners, therefore he recommended the need to establish healthy and functioning stadiums with low pollution.

Most research sample responses confirmed approval rate ranged between (92.67: 94.67\%) on the need to keep the fence height not less than 1.8 meters of bricks or rubble. In addition to the thick wall of trees, with a proper system of protection and security providing the necessary equipment and systems.

This is confirmed by the Universal Declaration of Human Rights (United Nations General Assembly, 1948) where it is stated that sports is a human right in practicing in a healthy environment as sport do not achieve their objectives or purposes unless good environmental conditions are met [4]

Most research sample responses also agreed with percentage ranged between (92.67: 94.67\%) about the necessity to prepare an environmental record established in accordance with the Law No. 4 of 1994 Arab Republic of Egypt (1994) concerned with environmental protection and its bylaws, and the need for environmental impact assessment to be checked by Environmental Affairs to express an opinion prior before allocating the site with coordination with Egyptian Environment Affairs Authority (EEAA)

Most research sample responses also agreed with a percentage between (90.00: 92.67\%), about the necessity of implementing assessment studies and sending them to the environmental affairs for review and comment prior customizing the site in accordance WTO suitable technical and environmental foundations. This was emphasized in (Mohsen Mohamed, 2009) [10] study which recommended the need to enact agricultural laws which restrict behavior deterrent abusers of ecological balance, who put the environment at risk of contamination either by factories or cars smoke in roads , public spaces or urban areas.

The Third aspect: Legislation and laws about managing the surrounding aerobic environment for athletic institutions

Table (3)

Frequencies, percentages and Chi square values for research sample responses 
For The Third aspect statements $(n=150)$

\begin{tabular}{|l|l|l|l|l|l|}
\hline Statement N & Yes & \multicolumn{3}{l}{ No } & Chi square v \\
\hline & Frequency & \% & Frequency & \% & \\
\hline 26 & 143 & 95.33 & 7 & 4.67 & 123.31 \\
\hline $26 \mathrm{~A}$ & 138 & 92.00 & 12 & 8.00 & 105.84 \\
\hline $26 \mathrm{~b}$ & 135 & 90.00 & 15 & 10.00 & 96.00 \\
\hline 27 & 142 & 94.67 & 8 & 5.33 & 119.71 \\
\hline $27 \mathrm{~A}$ & 139 & 92.67 & 11 & 7.33 & 109.23 \\
\hline $27 \mathrm{~b}$ & 138 & 92.00 & 12 & 8.00 & 105.84 \\
\hline 28 & 142 & 94.67 & 8 & 5.33 & 119.71 \\
\hline $28 \mathrm{~A}$ & 135 & 90.00 & 15 & 10.00 & 96.00 \\
\hline $28 \mathrm{~b}$ & 139 & 92.67 & 11 & 7.33 & 109.23 \\
\hline $28 \mathrm{c}$ & 135 & 90.00 & 15 & 10.00 & 96.00 \\
\hline $28 \mathrm{~d}$ & 139 & 92.67 & 11 & 7.33 & 109.23 \\
\hline $28 \mathrm{E}$ & 135 & 90.00 & 15 & 10.00 & 96.00 \\
\hline 29 & 135 & 90.00 & 15 & 10.00 & 96.00 \\
\hline $29 \mathrm{~A}$ & 142 & 94.67 & 8 & 5.33 & 119.71 \\
\hline $29 \mathrm{~b}$ & 139 & 92.67 & 11 & 7.33 & 109.23 \\
\hline $29 \mathrm{c}$ & 138 & 92.00 & 12 & 8.00 & 105.84 \\
\hline $29 \mathrm{~d}$ & 135 & 90.00 & 15 & 10.00 & 96.00 \\
\hline
\end{tabular}

Chi square significant at (0.05) level $=5.99$

Table (3) shows Chi square calculated values results are greater than its tabulated value at (0.05) significance level, which indicates the presence of statistically significant differences between the research sample responses, in favor of yes response.

Most research sample responses agreed with percentage ranged between (90.00: 95.33\%), Awareness of Legislation and laws on environmental management for sustainable development in the institutions for the purpose of protecting the environment from pollution and the possibility to practice sport activities depends on the choice of the site of the project or the athlete institution, ensuring not to exceed the permitted air pollutants, and rationing the overall pollution resulting from the total organizations in the area and ensure it is in the authorized border .

Most research sample responses also agreed with percentage ranged between (90.00: 94.67\%), that the allowable limits for air pollutants in emissions from different sources as defined by environment law are gaseous impurities, or solid or liquid, and air pollutants such as steam emitted from chimneys of industrial plants and incinerators of hospital vehicles, machinery and engines. 
Second article of the Environment Law stresses that every change in the properties of the natural air is a risk to human health and the environment, whether this pollution caused by natural factors or human activities. Therefore, the law requires owners in article No.44 to take necessary measures to maintain the degree of heat and humidity in work within the allowable limit. In case of necessity entity must ensure the appropriate safety measures for employees like special uniforms and other means of protection. (El-Henawi, 2004), (Environment Law, 1994). [6] [8]

Most research sample responses also agreed with a percentage between (90.00: 94.67\%) that athletic institutions management should be aware of the maximum limits for solid particles emissions from industrial plants' chimneys.

Most research sample responses with percentage ranged between (90.00: 94.67\%), which refers to the necessity of recognizing laws and regulations to achieve the sustainable development requirements and specifications for selecting and creating projects and organizations, recycling and garbage treatment factories, disposal wastes by sanitary landfill methods, means of collecting and transporting garbage chimneys heights conditions. This is confirmed by 37 and 40 Article, which states garbage and solid waste dumping, treatment or burning only in designated areas which is away from residential, industrial and agricultural areas. The implementing regulation of this law shows the chimneys' specifications of smoke, gases and vapors emitted from combustion process . (Environment Law, 1994). [8]

\section{Conclusions}

\section{In light of study results, research team concluded the following}

First: defining the concept of environmental management in Athletic institutions has been set which is a systematical care for aerobic environment to guarantee society economic aspects sustainment.

Second: determining the concept and the importance of managing the surrounding aerobic environment in athletic institutions in order to protect the environment. Environmental activities were completely declared during a specific time period during the preparation of the environmental performance report to activate environment control and follow-up function.

Third: Requirements and specifications for choosing and building projects in athletic institutions as the chosen location of the project according to specifications, controls and minimum distance from these areas in accordance with the provisions of Article (38) of the Environment Act.

Fourth: Legislation and laws about managing the surrounding aerobic environment for athletic institutions as the commitment of permissible limits of air pollutants in emissions as defined by the Environmental Law for gaseous, solid or liquid impurities.

\section{Recommendations}

From results presentation, discussion and conclusions, we recommend the following: - 
For various sporting institutions officials' managers, "the Ministry of Youth and Sports National Olympic Committee - Olympic sports and non-Olympic federations - sports clubs - youth centers - specific sports federations (Police Sports Association - Military Sports Federation).

1- Applying the proposed model for Legal regulations for managing the surrounding aerobic environment in Athletic institutions in order to achieve sustainable development

2- Raising the level of environmental awareness among officials of various athletes' institutions to avoid the risk of ignorance of environment preserving importance and facing the pollution cases through the organization through holding of a number of seminars and training courses.

3 - Claiming assessment of new organizations to assess environmental impact of the organization before starting to build sports facility or project.

4- Continuous assessment of organizations that received ISO 14000 - ISO 14001, for its compliance with environmental laws and legislation.

5- Coordination between Egyptian Environmental Affairs Authority (EEAA) and the ministries of interior, industry, health, oil and Sports, and developing the necessary laws to protect the environment from attacks that can be located on any of its elements.

6- Formation of a committee assessing the environmental damage and to identify its tasks in athletes institutions.

7- Establishing sports projects study environmental impact assessment study and send it to the EEAA for review and express an opinion prior to allocating the site.

\section{References}

1-Abdel Ghani, Noaman .Environment and Sports, the International Society for Arab translators. 2009. available at:

http://www.wata.cc/forums/showthread.php?50994;accessed on 02.01.2014

2-Al-Shafi'i, Hassan Atiya .sustainable development and environmental accounting and auditing on physical education and sport, first edition, Dar Al meet minimum printing and publishing, Alexandria, p $162 ; 2012$

3-Al-Shafi'i, Hassan Atiya . human rights law, the child in physical education and sport ", first edition, Dar Al meet minimum printing and publishing, Alexandria, p 325 ; 2005

4-Binta, Jibreen .2009. available at:

http://www.greenline.com.kw/ArtideDetails.aspx?tp=1955; accessed on 10.01.2014 
5-El-Henawi, Essam .Environmental issues in a hundred question and answers, technical publications, environment and development, Beirut. P 188-189 ;2004

6-Elsafy, Asaad Adnan Aziz .The effect of air pollution in some blood physiological and biochemical variables and some physical abilities, Journal of Physical Education Science, Volume III, issue (4). 2010; 123-136

7-El-Saud, Rateb .Human and environment (Study in environmental education), Dar Al-Hamed, Oman. 2004, 198-202

8-Environment Law No 4, Official Journal, No5, February $3^{\text {rd }}$. Arab republic of Egypt .1994

9-Hashem, Ali Hussein.The impact of environmental pollution on Child's mental and physical health, Faculty of Physical Education, Qadisiyah University, 2010 avialavle at: Http://www.husseinmardan.com/DrAliAlzamili-01.htm. ; accessed on 8.01.2014

10-Hashish, Hmemh Ibrahim \& Al-Din, Samah Ahmed Salah\& Abdel-Aziz, Donia Mohamed Adel requirements for applying sustainable development investment projects in sports organizations, research published in scientific sports universities Arabic - perspectives and aspirations. P 36-40 ;2010

11-ISO 14001 standard.

12-Law bodies for youth and sport, 2000.

13-Moussa, Moussa Ibrahim .Enviromental Information System in Rab Rpublic of Egypt, $2^{\text {nd }}$ Arabic conference: Enviromental management in local management systems in Arab World, Sharja, UAE, 2123 January ;2003

14-Mustafa, Mohammed Samir. Management of natural resources in light of environmental sustainability and the Millennium Development Goals, the Institute of National Planning, Cairo. P 11 ;2012

15- Qader, Mohsen Mohammad Amin .Environmental education and awareness and tax effect on reducing environmental pollution, Master thesis in Environmental Sciences, Faculty of Management and Economics, Department of Environmental Management, the Arab Academy, Denmark. P 85-86 ; 2009

16-The second Gulf Conference on sport and environment in local and regional tournaments for the Gulf Cooperation Council in Doha. 2011 _ available at: //www.ngoce,org;accessed on 10.01.2014

17-United Nations General Assembly Universal Declaration of Human Rights.1948 